\title{
Impact of climate change on sorghum productivity in India and its adaptation strategies
}

\author{
V. M. SANDEEP, V. U. M. RAO, B. BAPUJI RAO, G. BHARATHI ${ }^{1}$, V. P. PRAMOD, \\ P. SANTHIBHUSHAN CHOWDARY, N.R. PATEL ${ }^{2}$, P.MUKESH ${ }^{3}$ and P. VIJAYA KUMAR
}

\author{
Central Research Institute for Dryland Agriculture, Hyderabad - 500059 \\ ${ }^{1}$ Department of Meteorology and Oceanography, Andhra University, Visakhapatnam - 530004 \\ ${ }^{2}$ Indian Institute of Remote Sensing, Dehradun- 248001 \\ ${ }_{3}^{3}$ Indian institute of Millets Research Hyderabad, Rajendra Nagar, Hyderabad- 500030
}

\begin{abstract}
Future climate change projections for India indicate distinct rise in temperature and increased variability in rainfall. This study aims to assess the impact of climate change on sorghum productivity in India in future climatic periods (2025, 2050 and 2075) using DSSAT-sorghum and suggest adaptation strategies to negate the negative impact of climate change on sorghum productivity in the future climates. Three CMIP-5 climate models (GFDL-ESM2M, MIROC5 and NorESM1-M) generated weather data for three future periods were used at various locations for kharif (Akola, Dharwad, Surat and Udaipur) and rabi (Bijapur, Dharwad, Rahuri and Solapur) seasons to simulate sorghum yields. Projected changes in day-night temperatures and rainfall during kharif and rabi growing seasons at these locations are diverse both in direction and magnitude. Increasing trend in rainfall is observed during both crop seasons towards the end of $21^{\text {st }}$ century. Sorghum crop is likely to experience warmer temperature in the second half of the century and rise in minimum temperature is more explicit than maximum temperature at all the locations. Location specific management options can be adopted to mitigate the negative impacts of the change in climate in future projected scenarios, as they are found beneficial.
\end{abstract}

Keywords : Climate change, DSSAT, sorghum, adaptation strategies, India

Sorghum is one of the major cereal crop grown mostly under rainfed condition and it continued to be main staple food for marginal farmers of developing countries in Asia and Africa (Murthy et al., 2007). Due to its higher drought tolerance over other cereal crops, sorghum is highly suitable to Semi Arid Tropic (SAT) crop production system (Ludlow and Muchow, 1990). In India 5.45 million tons (3.14 million tons during rabi and 2.31 million tons during kharif seasons) of sorghum is produced from 6.18 million hectares (DACNET 2016). The sorghum productivity in India is far low (864 $\left.\mathrm{kg} \mathrm{ha}^{-1}\right)$ compared to global average $\left(1481 \mathrm{~kg} \mathrm{ha}^{-1}\right)$ (FAOSTAT, 2016). Since sorghum is cultivated majorly as a rainfed crop, its productivity is significantly influenced by climatic elements (Srivastava et al., 2010). Grain sorghum yield is extremely influenced by crop management practices, growing-season rainfall amount and its distribution, soil water content at planting, plant-available water and other climatic conditions (Assefa et al., 2010). Varshneya et al., (2004) pointed out that sorghum phenology is inversely proportional to change in temperature and grain yield is directly proportional to change in rainfall. Sandeep et al.,
(2017) have reported increasing trend in the water requirement of sorghum over majority of sorghum growing regions both in kharif and rabi season during 2050 to 2080 inspite of increasing trend in rainfall.

Crop growth simulation models (CGSMs) are widely used to study the impact of climate change on crop productivity. Climate change impact studies involving rabi sorghum projected a decline in yield up to 7 per cent by 2020 , up to 11 per cent by 2050 and up to 32 per cent by 2080 (Srivastava et al., 2010) over the base period 19781999. Decline in sorghum productivity in future climate change scenarios at different locations of India was primarily attributed to reduction in crop growth period with increase in temperature (Boomiraj et al., 2012). Pramod et al. (2017) used various adaptation strategies viz change in sowing dates, applying additional irrigation and fertilizer to minimize the yield reduction in wheat in India. In this background an attempts has been made to study the impact of climate change on sorghum yield and to quantity the benefits of adaptation strategies like changing sowing time, irrigation scheduling on the productivity of sorghum for kharif and 
Table 1: Geographic and agro-climatic features of different sites

\begin{tabular}{lllcrrrr}
\hline Season & Location & Latitude & Longitude & $\begin{array}{r}\text { Altitude } \\
\text { (AMSL) }\end{array}$ & $\begin{array}{r}\text { Seasonal } \\
\text { rainfall }(\mathrm{mm})\end{array}$ & $\begin{array}{r}\text { Seasonal } \\
\text { average } \\
\text { Tmax }\left({ }^{\circ} \mathrm{C}\right)\end{array}$ & $\begin{array}{r}\text { Seasonal } \\
\text { average } \\
\text { Tmin }\left({ }^{\circ} \mathrm{C}\right)\end{array}$ \\
\hline Kharif & Akola & 20.70 & 77.02 & 296 & 712 & 33.2 & 24.1 \\
& Dharwad & 15.27 & 75.05 & 731 & 478 & 29.5 & 21.1 \\
& Surat & 21.10 & 72.49 & 12 & 1393 & 33.2 & 25.4 \\
& Udaipur & 24.35 & 73.42 & 573 & 603 & 32.6 & 23.2 \\
\multirow{2}{*}{ Rabi } & Bijapur & 16.49 & 75.42 & 614 & 186 & 31.2 & 18.3 \\
& Dharwad & 15.27 & 75.05 & 731 & 204 & 30.3 & 17.8 \\
& Rahuri & 19.23 & 74.38 & 516 & 156 & 31.2 & 14.4 \\
& Solapur & 17.39 & 75.54 & 474 & 121 & 32.1 & 16.4 \\
\hline
\end{tabular}

rabi seasons in future climate scenarios $(2025,2050$ and 2075) using DSSAT-Sorghum model.

\section{MATERIALS AND METHODS}

\section{Study area}

In the present study four representative locations were selected each for kharif and rabi seasons. The major kharif sorghum growing regions are extended between the states of Rajasthan (North) to Karnataka (South). We selected Akola (Central), Dharwad (South), Surat (West) and Udaipur (North) for kharif season. The major rabi sorghum growing regions are confined to Deccan Plateau, Western and Central India. We selected Rahuri, Solapur, Dharwad and Bijapur (South) for rabi seasons. These locations are selected on the basis of data availability and their climate/soil regimes. The geographical/seasonal climatic characteristics and soil/ experimental details of the selected locations are furnished in Table 1 and Table 2 respectively. Site wise daily weather data on maximum and minimum temperature, rainfall and sunshine hours apart from crop and soil data were collected and used in DSSAT-Sorghum model simulations. Replicated trials widely cultivated Indian sorghum genotypes (CSH-9, CSH-16) during the kharif and (M-35-1) during the rabi were conducted at all the locations.

\section{CERES-Sorghum model}

CERES- Sorghum, a process-based and managementoriented crop simulation model embedded in Decision Support for Agrotechnology Transfer (DSSAT) platform was used for sorghum yield simulations. The genotypic coefficients for various sorghum cultivars were chosen by repeated iterations using field experimental data for the different locations until a close match between simulated and observed yield was attained. Model efficiency was determined by comparing observed and simulated yields using statistical tools like root mean square error (RMSE) and D-index.

\section{Climate change projections and adaptation strategies}

The projected daily weather datasets were sourced from three global general circulation models (GCMs) from coupled model inter comparison project-5(CMIP-5) in RCP 4.5 scenarios viz., GFDL-ESM2M, MIROC5 and NorESM1$\mathrm{M}$, which were found suitable for Indian conditions (Pramod et al., 2017) for the years 2025, 2050 and 2075 for the selected locations. The projected $\mathrm{CO}_{2}$ concentrations in RCP 4.5 were 440, 530 and 570 ppm by 2025, 2050 and $2075 \mathrm{~s}$, respectively, and were used in simulating the future sorghum yields, while measured concentration was used for the baseline period. The projected daily weather data viz., daily rainfall, maximum temperature $\left(\mathrm{T}_{\max }\right)$, minimum temperature $\left(\mathrm{T}_{\text {min }}\right)$ and solar radiation from GCMs, were sourced from MarkSim DSSAT weather file generator (http:/ /gisweb.ciat.cgiar.org/MarkSimGCM/).

In the present study, three crop management options viz., (1) six sowing time options $(15,10,5$ days ahead and $5,10,15$ days delayed relative to normal sowing time) as the first low-cost option tried and to chose the one which provides the highest yield, (2) one additional irrigation of 50 $\mathrm{mm}$ at 45-60 days after sowing (DAS) and (3) change in sowing time combined with additional irrigation, were tested as adaptation strategies to sustain sorghum productivity for $k$ harif and rabi seasons in future climates. The net effect of each adaptation strategy was assessed in terms of relative yield as

Relative yield $=\left(\frac{\mathrm{Y}_{f a}-\mathrm{Y}_{b}}{\mathrm{Y}_{b}}\right) * 100$ 


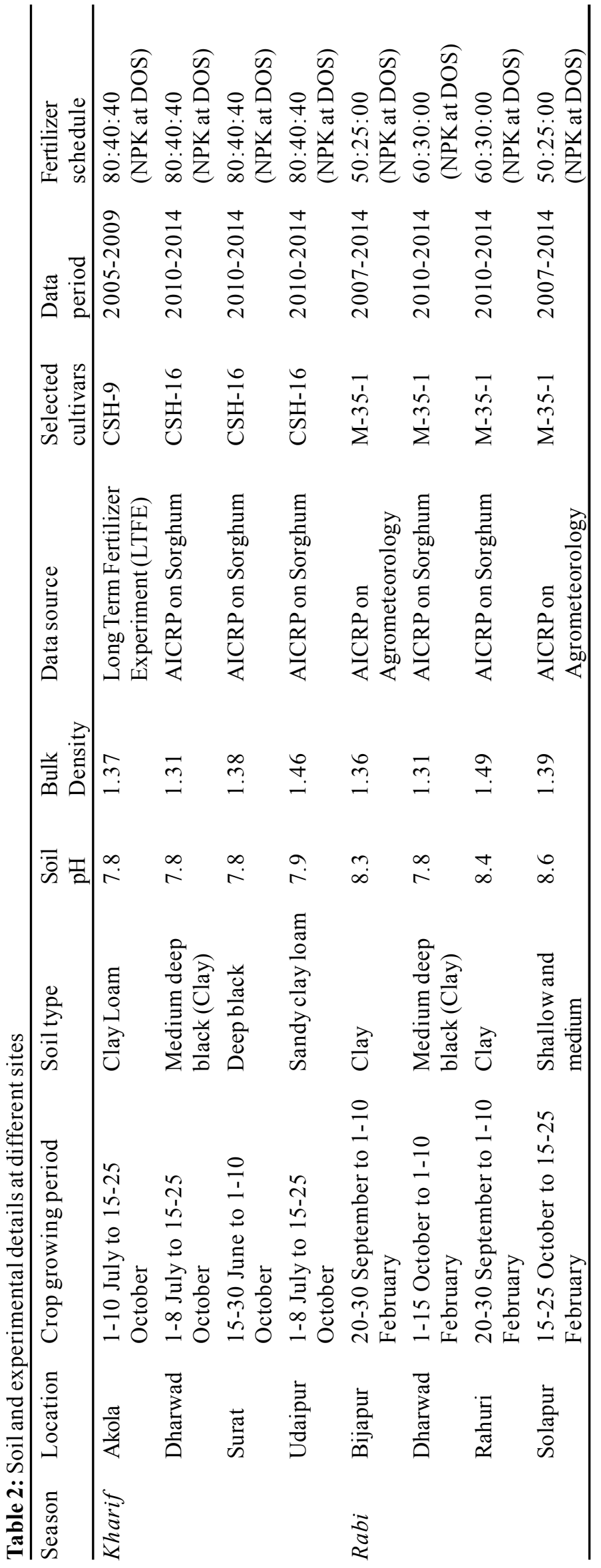

Where $\mathrm{Y}_{\mathrm{fa}}$ indicates future yield due to adaptation and $\mathrm{Y}_{\mathrm{b}}$ indicates baseline yield without any adaptation. The combination(s), which gave the highest relative yield at each site in each scenario, was considered as the best suitable adaptation option (Pramod et al., 2017). While simulating crop yields in future climates technological advancements in crop management, as well as impacts of pest and diseases on crop production, are not considered.

\section{RESULTS AND DISCUSSION}

\section{Calibration of CERES-Sorghum}

The CERES-Sorghum model was calibrated for different sorghum cultivars (CSH-9, CHS 16) for kharif and (M-35-1) for rabi seasons based on data from field experiments carried out at respective experimental locations. Cultivar specific genotypic coefficients were estimated by the GENCALC software embedded in DSSAT v4.6 and the calibrated genetic coefficients of various sorghum cultivars at respective sites are presented in Table 3.The CERESSorghum model satisfactorily simulated the phenology and grain yield of sorghum cultivars in close match with observed values at different locations for both kharif and rabi seasons (Table 4). The differences with measured values are well within acceptable error level as indicated by a very high value of D-Index and acceptable RMSE values.

\section{Climate change projections at different sites}

The average percentage change in $\mathrm{T}_{\max }, \mathrm{T}_{\min }$ and rainfall projected by three models over baseline during the sorghum growing seasons (kharif and rabi) in 2025, 2050 and 2075 at four respective experimental sites are summarized in Table 5. The rise in $\mathrm{T}_{\min }$ more severe in comparison with $\mathrm{T}_{\max }$ over all the locations in future climatic periods during both (kharif and rabi) crop growing seasons. Rainfall (kharif and rabi seasons) is projected to be below normal during 2025 and expected to increase towards 2075 at all locations. Sorghum crop is likely to receive more rainfall at Dharwad $(+18 \%$ and $+28 \%$ during kharif and rabi crop seasons respectively) by 2075 . The kharif season sorghum crop experience warmest day and night temperatures at Dharwad $(+11 \%$ and $+14 \%)$ and Udaipur ( $+10 \%$ and $17 \%)$, while rabi season sorghum crop may experience warmest daytime temperature at Bijapur $(+10 \%)$ followed by Solapur $(+10 \%)$ and warmest nights at Dharwad $(+20 \%)$ followed by Bijapur $(+18 \%)$ towards the end of $21^{\text {st }}$ century. 
Table 3: Genotypic coefficients used for selected sorghum cultivars for rainy and post rainy seasons

\begin{tabular}{|c|c|c|c|c|c|c|c|c|c|c|c|c|}
\hline Station & Variety & $\mathrm{P} 1$ & $\mathrm{P} 2$ & $\mathrm{P} 2 \mathrm{O}$ & $\mathrm{P} 2 \mathrm{R}$ & PANTH & $\mathrm{P} 3$ & $\mathrm{P} 4$ & P5 & PHINT & G1 & $\mathrm{G} 2$ \\
\hline \multicolumn{13}{|c|}{ Rainy season } \\
\hline Akola & CSH-9 & 680 & 100 & 16.5 & 125 & 617.5 & 152.5 & 81.5 & 500 & 49 & 20 & 6 \\
\hline Dharwad & CSH-16 & 300.5 & 102 & 16 & 270 & 617.5 & 152.5 & 81.5 & 700 & 49 & 18 & 4.5 \\
\hline Surat & CSH-16 & 470.5 & 102 & 16 & 170 & 617.5 & 152.5 & 81.5 & 700 & 49 & 22 & 6 \\
\hline Udaipur & CSH-16 & 505 & 102 & 17 & 295 & 617.5 & 152.5 & 81.5 & 600 & 49 & 22 & 6 \\
\hline \multicolumn{13}{|c|}{ Post rainy season } \\
\hline Bijapur & M-35-1 & 236 & 102 & 17 & 95.6 & 617.5 & 152.5 & 81.5 & 540 & 49 & 12 & 6 \\
\hline Dharwad & M-35-1 & 310 & 102 & 16 & 195.6 & 617.5 & 152.5 & 81.5 & 540 & 49 & 22 & 6 \\
\hline Rahuri & M-35-1 & 305 & 102 & 13 & 55.6 & 617.5 & 152.5 & 81.5 & 446 & 49 & 22 & 6 \\
\hline Solapur & M-35-1 & 280 & 102 & 15 & 155.6 & 617.5 & 152.5 & 81.5 & 540 & 49 & 13 & 6 \\
\hline
\end{tabular}

P1-Thermal time from seedling emergence to the end of the juvenile phase (expressed in degree days above TBASE during which the plant is not responsive to changes in photoperiod, P2-Thermal time from the end of the juvenile stage to tassel initiation under short days (degree days above TBASE), P2O-Critical photoperiod or the longest day length (in hours) at which development occurs at a maximum rate, P2R-Extent to which phasic development leading to panicle initiation (expressed in degree days) is delayed for each hour increase in photoperiod above P2O, PANTH-Thermal time from the end of tassel initiation to anthesis (degree days above TBASE), P3-Thermal time from to end of flag leaf expansion to anthesis (degree days above TBASE), P4-Thermal time from anthesis to beginning grain filling (degree days above TBASE), P5-Thermal time from beginning of grain filling to physiological maturity (degree days above TBASE), PHINT-Phylochron interval; the interval in thermal time between successive leaf tip appearances (degree days), G1-Scaler for relative leaf size, G2- Scaler for partitioning of assimilates to the panicle (head).

\section{Simulated future sorghum yield without any adaptation strategies}

The future sorghum yields for kharif and rabi seasons simulated using different climate change scenarios (GFDLESM2M, MIROC5, and NorESM1-M) with the existing fertilizer (100\% NPK) at each experimental site without any adaptation strategies indicate that during the first quarter of the $21^{\text {st }}$ century (2025) the mean relative yield is achieved at Akola and Dharwad with existing crop management practices, while by middle of the $21^{\text {st }}$ century (2050) it is confined only to Akola (Table 6). By the end of this century (2075) kharif sorghum yields are declined at all the selected locations. From Table 5 it is evident that the temperature is above normal over all the locations except during 2025, 2050 at Akola and during 2025 at Dharwad. Due to the increase in temperature as discussed in earlier section, the length of growing period is declining resulting in reduced yields. A decline of 4 days and 2 days in crop duration is simulated at Udaipur and Surat respectively and it causes a drop in yield about 10 per cent at Udaipur and 4 per cent at Surat in 2025. In 2050 the crop duration decreased up to 2 days with reduced yield of 13 per cent at Udaipur, 7 days with reduced yield about 6 per cent at Dharwad and Surat.
Further a marked decline in growing period is simulated at Dharwad ( 8 days), followed by Udaipur ( 7 days), Surat ( 7 days) and Akola (5 days) in 2075. A decline in yield is noticed about 3 per cent at Akola, 14 per cent at Dharwad, 3 per cent at Surat and 13 per cent at Udaipur in 2075.

The rabi season sorghum yield (Table 6) and length of growing period (Table 5) also shows signs of decreasing trend in future climatic scenarios over all the locations except Bijapur and Rahuri during 2050. The average temperature during the crop growing seasons is above normal in future climatic scenarios over all the locations. A marked decrease of crop duration at Dharwad (8 days) followed by Bijapur ( 7 days), Rahuri (4 days) and Solapur ( 4 days) in 2025 is projected. Areduction in yield about 20 per centat Bijapur, 16 per cent at Dharwad, 10 per cent at Rahuri and 13 per cent at Solapur is simulated in 2025. The crop duration is further decreased by 9 days and 2 days at Dharwad and Solapur respectively in 2050 with a decline in yield by 22 per cent at Dharwad and 4 per cent at Solapur. A further decrease in season length is simulated up to 9 days at Dharwad and Bijapur as well as 5 days at Rahuri and Solapur in 2075. Yield reductions are simulated about 22 per cent at Bijapur, 23 percent at Dharwad, 7 per cent at Rahuri 
Table 4: Observed and simulated crop phenology and grain yields during baseline period

\begin{tabular}{|c|c|c|c|c|c|c|c|c|}
\hline \multirow[t]{2}{*}{ Season } & \multirow[t]{2}{*}{ Parameter } & \multirow[t]{2}{*}{ Station } & \multicolumn{2}{|c|}{ Mean } & \multicolumn{2}{|c|}{ Standard Deviation } & \multirow[t]{2}{*}{ D-Index } & \multirow[t]{2}{*}{ RMSE } \\
\hline & & & Observed & Estimated & Observed & $\overline{\text { Estimated }}$ & & \\
\hline \multirow[t]{12}{*}{ Kharif } & \multirow[t]{4}{*}{ Anthesis day } & Akola & 74 & 75 & 3.57 & 2.07 & 0.87 & 1.84 \\
\hline & & Dharwad & 71 & 73 & 1.3 & 1.6 & 0.7 & 1.8 \\
\hline & & Surat & 64 & 64 & 2 & 2.07 & 0.8 & 1.5 \\
\hline & & Udaipur & 74 & 76 & 6.44 & 4.39 & 0.86 & 3.8 \\
\hline & \multirow[t]{4}{*}{ Maturity day } & Akola & 112 & 108 & 4.32 & 3.3 & 0.59 & 4.1 \\
\hline & & Dharwad & 111 & 112 & 2.3 & 3.67 & 0.78 & 2.4 \\
\hline & & Surat & 105 & 103 & 1.3 & 2.38 & 0.68 & 2.7 \\
\hline & & Udaipur & 114 & 113 & 1.92 & 4.5 & 0.79 & 2.5 \\
\hline & \multirow[t]{4}{*}{ Yield $\left(\mathrm{kg} \mathrm{ha}^{-1}\right)$} & Akola & 4143 & 3672 & 980 & 699 & 0.81 & 734.2 \\
\hline & & Dharwad & 4354 & 4150 & 946 & 614 & 0.77 & 646.5 \\
\hline & & Surat & 3493 & 3291 & 310 & 256 & 0.65 & 320.2 \\
\hline & & Udaipur & 4602 & 4406 & 1356 & 668 & 0.74 & 650.6 \\
\hline \multirow[t]{12}{*}{ Rabi } & \multirow[t]{4}{*}{ Anthesis day } & Bijapur & 62 & 61 & 1.58 & 1.67 & 0.66 & 2.16 \\
\hline & & Dharwad & 65 & 66 & 2.65 & 2.06 & 0.77 & 1.94 \\
\hline & & Rahuri & 64 & 65 & 2.58 & 3.2 & 0.85 & 1.8 \\
\hline & & Solapur & 59 & 56 & 3.7 & 1.8 & 0.62 & 4.7 \\
\hline & \multirow[t]{4}{*}{ Maturity day } & Bijapur & 105 & 102 & 2.56 & 2.73 & 0.67 & 3.82 \\
\hline & & Dharwad & 109 & 112 & 3.11 & 3.81 & 0.77 & 3.4 \\
\hline & & Rahuri & 109 & 108 & 3.16 & 2.55 & 0.75 & 2.55 \\
\hline & & Solapur & 98 & 97 & 3.38 & 3.2 & 0.59 & 4.2 \\
\hline & \multirow[t]{4}{*}{ Yield $\left(\mathrm{kg} \mathrm{ha}^{-1}\right)$} & Bijapur & 1378 & 1573 & 507 & 567 & 0.72 & 441.8 \\
\hline & & Dharwad & 2832 & 2692 & 1304 & 618 & 0.8 & 754.7 \\
\hline & & Rahuri & 2088 & 2346 & 386 & 356 & 0.61 & 436.4 \\
\hline & & Solapur & 1034 & 1376 & 221 & 143 & 0.51 & 243.2 \\
\hline
\end{tabular}

and 14 per cent at Solapur in 2075.

\section{Impact of adaptation strategies}

The average magnitude of improvement (\%) in grain yield (mean of the three selected projected scenarios) by the various adaptation strategies in future climatic periods for kharif and rabi sorghum are furnished in Table 6. The influence of delayed sowing is found negatively on kharif and rabi yield over all the locations in future climatic scenarios, so the results are not provided here.

Kharif crop: The impact of six different sowing dates (three early and three late sowings at an interval of five days) with respect to the normal date of sowing (DOS) at each experimental site was assessed. The application of additional irrigation with normal DOS is not found beneficial (Table 6).
Among the four sites, significant improvement and targeted kharif sorghum yield was attained at Surat during all the three future periods and over Akola in 2075 when sowing was advanced compared to the normal DOS. Due to the relatively small change in mean temperature the targeted yield is attained with normal DOS without any adaptation strategies at Akola in 2025 and 2050 and at Dharwad in 2025. The advancement of sowing date is able to achieve the targeted yield by alleviating temperature stress and ensure the availability of moisture in rainfed condition at Akola in 2075 and at Surat in all the future periods. Due to the comparatively steep rise in temperature over Udaipur in all the future periods and at Dharwad in $2050 \& 2075$, the advancement of sowing time combined with an extra irrigation of $50 \mathrm{~mm}$ (45-60 DAS) is required to attain the targeted productivity. 


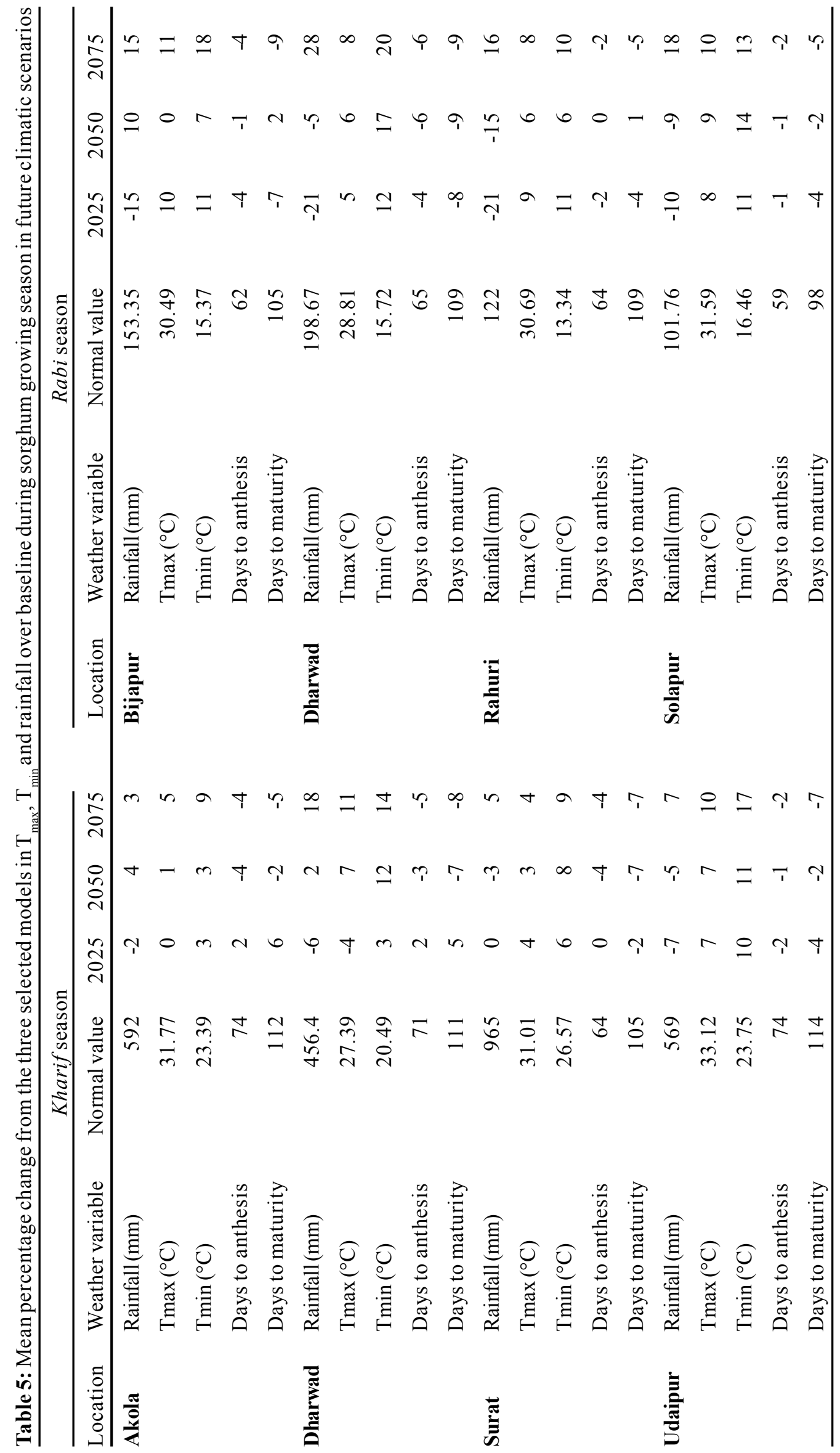


Table 6: Various adaptation strategies of kharif and rabi sorghum with average magnitude of advantage (\% grain yield) for different climate periods

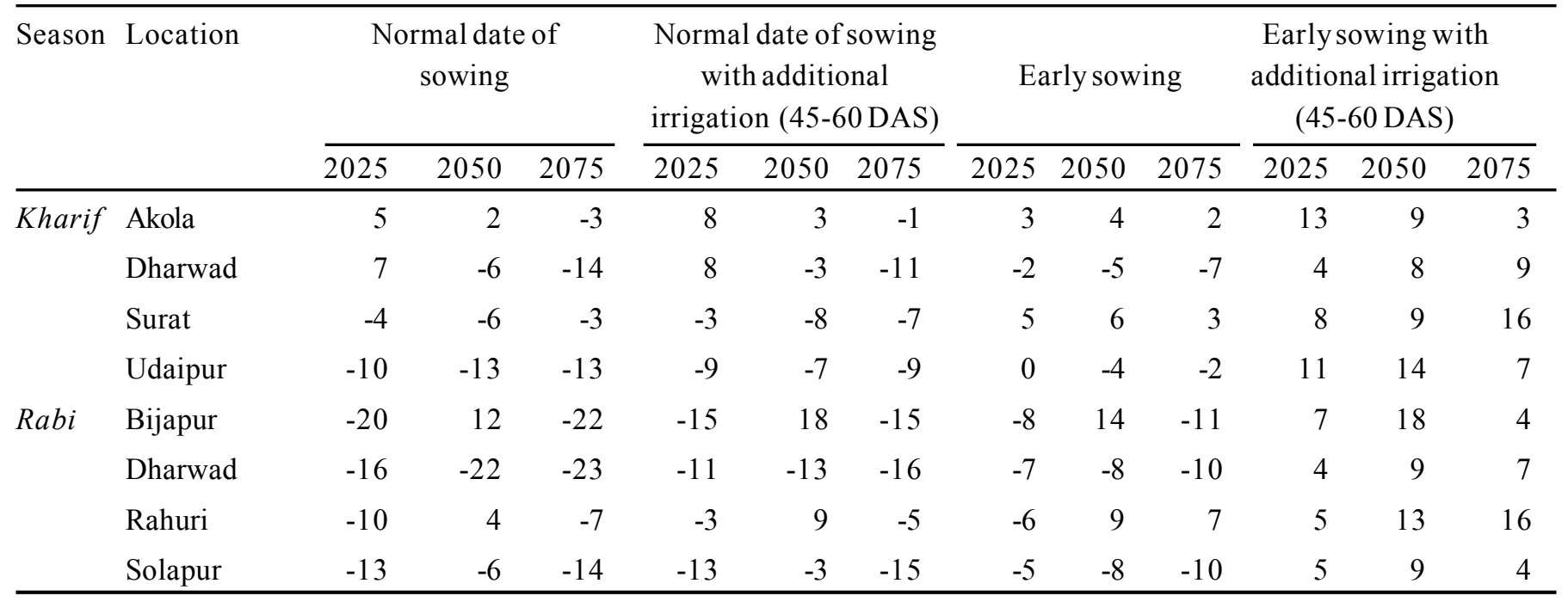

Rabi crop: Due to comparatively lower temperature stress at Bijapur and Rahuri in 2050 the targeted yield is attained in normal DOS without any adaptation strategies. The application of additional irrigation with normal DOS is found not beneficial adaptation strategy. The advancement of sowing date reduces the impact of temperature stress and facilitates to attain the targeted yield at Rahuri in 2075. Due to the higher rate of temperature stress advancement of sowing date combined with an extra irrigation of $50 \mathrm{~mm}$ (4560 DAS) is required to sustain the targeted yield at Rahuri in 2025, at Bijapur in 2025 and 2075 and in all the future periods at Solapur and Dharwad (Table 6). Though adjusting sowing time is the most widely studied strategy of adaptation (White et al., 2011), the impact by adjusting sowing time appears to be location specific as observed in the present study as the response is not uniform across the sites studied. The differential rise in day and night temperatures at different sites could be another reason for this response.

\section{CONCLUSIONS}

Calibrated and validated CERES-Sorghum model can be used to study the impact of climate change on sorghum yields for kharif and rabi seasons in India. Both kharif and rabi sorghum crop is likely to receive below normal rainfall in 2025 and projected to increase towards the end of the $21^{\text {st }}$ century. Sorghum crop may confront with warmer temperature in the second half of the century and the rise in night time is more severe than day time temperature over all the locations during both kharif and rabi seasons. By following existing crop management practices normal kharif yield is achieved at Akola and Dharwad in the first quarter of $21^{\text {st }}$ century and in the middle of the century it is confined only at Akola. The normal rabi sorghum yield is achieved in future climatic periods only at Bijapur and Rahuri during 2050. Both kharif and rabi sorghum yield is exhibiting a decreasing trend towards the end of the $21^{\text {st }}$ century. Negative influences of climatic change over sorghum growing areas of India can be minimized by adapting one or a combination of management practices like adjusting sowing time, application of extra irrigation which are location specific as obtained from the present study.

\section{REFERENCES}

Assefa, Y., Staggenborg, S.A. and Prasad, P.V.V.(2010). Grain sorghum water requirement and response to drought. Crop Management. doi: 10.1094/CM-2010-1109-01RV(KAES: 10-296-J).

Boomiraj, K., Marimuthu, S., Wani, S. P., Ravikumar, S., Manikandan ,N. and Tani, S. (2012). Vulnerability assessment of kharif rainfed sorghum to climate change in SAT regions of India, J. Agrometeorol., 14 (1): 2-8.

DACNET (2016). Latest APY State data, Directorate of Economics and Statistics, Government of India.http:// eands.dacnet.nic.in/PDF/5-Year_foodgrain201015.xls.

FAOSTAT (2016). Food and Agriculture Organization of the United Nations.http://faostat.fao.org/site/567/ default.aspx\#ancor. 
Ludlow, M.M. and Muchow, R.C. (1990). Acritical evaluation of traits for improved crop yields in water-limited environments. Adv. Agron., 43: 107-153.

Murthy, M.V.R., Piara Singh, Wani, S.P., Khairwal, I.S. and Srinivas, K. (2007). Yield gap analysis of sorghum and pearl millet in India using simulation modeling. Global Theme on Agroecosystems Report no. 37. International Crops Research Institute for the Semi-Arid Tropics, Patancheru 502324, Andhra Pradesh, India, 82 pp.

Pramod, V.P., Bapuji Rao, B., Ramakrishna, S.S.V.S., Muneshwar Singh, M., Patel, N.R, Sandeep, V.M., Rao, V.U.M, Chowdary, P.S, Narsimha Rao, N. and Vijaya Kumar, P. (2017). Impact of projected climate on wheat yield in India and its adaptation strategies. J. Agrometeorol., 19 (3): 207-216.
Sandeep, V. M., Bapuji Rao, B., Bharati, G., Rao, V.U.M., Pramod, V.P., Chowdary, P.S., Patel, N. R. and Vijayakumar, P. (2017). Projected future change in water requirement of grain sorghum in India. J. Agrometeorol., 19(3):217225.

Srivastava A, Naresh Kumar, S. and Aggarwal, P.K. (2010). Assessment onvulnerability of sorghum toclimate change in India, Agric. Ecosyst. Environ.,138: 160-169.

Varshneya, M.C., Sabale, R.N., Bote, N.L., Salunke, S.S., More, D.B. and Thanedar, P.V. (2004). Response of CERESSorghum model for different agroclimatic conditions. J.Agrometeorol., 6(1): 119-124.

White, J.W., Hoogenboom, G., Kimball, B.A. and Wall, G.W. (2011). Methodologies for Simulating Impacts of Climate Change on Crop Production. Field Crops Res., 124: 357-368. 